\title{
PERCEIVED RESOURCE QUALITY AS A FRAMEWORK TO ANALYZE IMPACTS OF CLIMATE CHANGE ON ADVENTURE TOURISM: SNOW, SURF, WIND, AND WHITEWATER
}

\author{
RALF BUCKLEY \\ International Chair in Ecotourism Research, Griffith University, Gold Coast, Australia
}

\begin{abstract}
Surf, snow, wind, and whitewater provide natural resources for adventure tourism. Both the resources themselves, and access for tourism, are dependent on weather and hence are affected by climate change. For some adventure tourism subsectors (e.g., skiing and snowboarding) the industry has already responded to climate change, along with other pressures, by changing its geography and business models. In most subsectors, commercial tour operators perceive themselves as affected by short-term extreme weather events, and climate change models are not yet precise enough to predict how these will change over the short time horizons of tourism business planning. Some particular subsectors, however, can provide early warning indicators of industry responses to climate change. These include: heliskiing and heliboarding; professional big-wave surfing; and whitewater rafting and kayaking on snow melt, monsoon rainfall, or dam-release water flows. These responses may be detected through multiparameter models of visitor numbers and the geography of preferred sites or, more immediately, from the perceptions of commercial tourism operators involved in these subsectors.
\end{abstract}

Key words: Adventure tourism; Climate change; Impacts; Resource quality; Snow; Surf; Wind; Whitewater

\section{Introduction}

Many types of tourism, recreation and sport are heavily dependent on the weather, and are hence affected by climate change (Becken, 2013; Buckley, 2008a, 2008b; Buckley \& Shakeela, 2014; Buckley, Gretzel, Scott, Weaver, \& Becken, 2015; Day, Chin, Sydnor, \& Cherkauer, 2013; Goh, 20912; Gössling \& Hall, 2006; Gössling, Scott, Hall, Ceron, \& Dubois, 2012; Hall, 2015). Here I examine these effects for a specific set of adventure tourism activities, namely those involving nonmotorized boardsports and paddlesports that rely on wind or water. These are: snowboarding and skiing; surfing, sailboarding, and kiteboarding; and whitewater kayaking and rafting. These are "rush" activities (Buckley, 2012) that support substantial international commercial tourism industry subsectors (Buckley, 2006, 2007, 2010). I adopt a framework that treats snow, surf, wind, and whitewater as tourism resources of variable quality, 
and analyzes the effects of climate change on: the quality, geography, and seasonality of the physical resources, as perceived by adventure tourists; the human constraints on access to those resources by adventure tourists; and the interactions between the physical and human factors.

A recent review by Rosselo-Nadal (2014) noted that three main different theoretical approaches have been applied to date in evaluating the effects of climate change on tourism. These involve physical change, climatic index, and tourism demand models respectively, with tourism demand models subdivided into time series, discrete choice, and aggregate demand approaches (Table 1). Physical change models focus on the local physical environments within which tourism enterprises and stakeholders operate, and how the characteristics of those local environments are modified by broader scale climate change. For example, more frequent extreme weather events may cause fires, floods, droughts, or storms and beach erosion. Climatic index models adopt a broader scale approach to human physical comfort. For example, they treat northern hemisphere winter "sun-sand-sea" destinations as a means to improve climatic comfort. The generally do not incorporate factors such as air conditioning in tropical destinations, or the attractiveness of snow sports and indoor social events in winter (Buckley, 2008a). Tourism demand approaches either track or tourist numbers to different destinations in parallel with weather parameters, or model tourist choices between destinations in relation to weather and climate.

\section{Method}

The framework adopted here (Fig. 1) is an evolution of previous physical change models, with three additional components. The first is that, from a tourism perspective, what matters is not only the physical change itself, but how the changed physical environment is perceived by a particular group of tourists. For this analysis, this group consists of practitioners in the adventure activities examined, with various degrees of specialist expertise.

The second additional component is that these tourists consider not only a single destination and activity, but a large set of competing destinations for the same activity, and competing activities at either the same or different destinations. As noted by Rosselo-Nadal (2014), "choosing a final destination is not an independent decision, but the final decision of a set of choices” (p. 337). In making these decisions, tourists compare expected resource quality for their preferred adventure activities, across a range of potential destinations.

As also noted by Rosselo-Nadal (2014, p. 335), the perceptions and preferences of tourists may change. He argues, for example, that "it is almost impossible to provide information on the changing preferences of potential tourists visiting mountain resorts over the next 50 years" (p. 335); but that "an assessment is needed of what tourists perceive to be optimal conditions, and a subsequent evaluation of future climate conditions will then determine a destination's diminished or improved attractiveness for tourists” (p. 335). The approach adopted here notes that despite these difficulties, some such changes have already been identified, and others can be projected.

The third additional component is that changes in tourist choices of activity and site are driven by many other factors besides resource quality: most notably, those related to access, infrastructure, safety, and price. In the short term, these factors can change much faster, and can greatly outweigh, the physical

Table 1

Previous Approaches, Each Taken Independently

\begin{tabular}{|c|c|c|}
\hline Principal & Secondary & Focus on \\
\hline Physical environment & - & Degree of suitability for intended activity \\
\hline Comfort index & - & Degree of climatic comfort for human body outdoors \\
\hline \multirow[t]{3}{*}{ Tourism demand } & Time series & Temporal correlations between climate variables and tourist numbers \\
\hline & Discrete choice & Economic choice models, bundle of features \\
\hline & Aggregate demand & Trade-offs between factors influencing demand \\
\hline
\end{tabular}

Summarized from Rossello-Nadal (2014). 


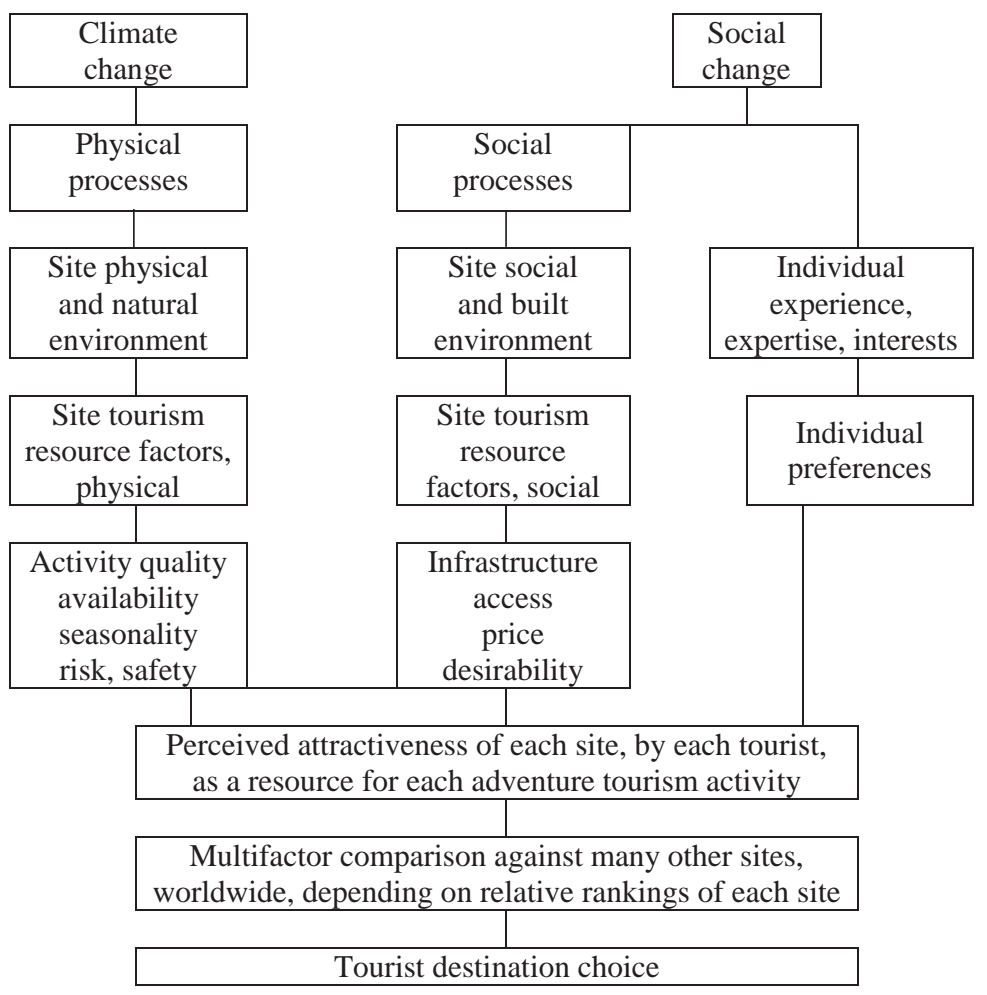

Figure 1. Framework for tourism resource approach.

effects produced by climate change. Time series, discrete choice, and aggregate demand models can include these rapidly changing factors, but physical change and climatic index models have been developed at longer timescales.

For the adventure tourism sector specifically, the framework adopted here is that snow, surf, wind, and whitewater are perceived by practitioners as weather-dependent resources for adventure tourism. These resources differ between sites, vary between seasons, and change between years. The quality of each of these resources is evaluated in considerable detail by individual adventure practitioners. Perceptions of quality differ between practitioners, depending on expertise, experience, and interests. The global geography and economics of adventure tourism is determined by the interaction between these physical factors and human social factors applicable across the entire tourism industry (Buckley, 2006, 2010; Buckley et al., 2015).

Under the framework adopted here, climate change influences weather patterns and trends, and these affect the various types of adventure tourism through several different mechanisms. First, climate change affects the short-term availability, timing, and quality of snow, surf, wind, and whitewater, which provide the basic natural resources for these types of adventure tourism. Second, climate change affects the risks and enjoyment associated with using natural resources for adventure tourism (e.g., through avalanche or flood risk, rain and ice, drought and fire, and wildlife populations and migrations). Third, in the slightly longer term, changes in weather patterns can influence physical terrain features, such as watercourses or coastal sandbars, affecting the value of individual sites for adventure tourism.

Fourth, climate change can modify the human or social factors, such as access to specific sites. For example, high-altitude airstrips or airports may become unusable because of increasing cloud and fog; parks agencies and other land managers may close access to particular sites because of increased risk of fire; or access roads may be blocked by 
floods or cut by landslides. Finally, relatively small physical changes at individual sites may change their position in the relative ranking of similar sites worldwide, with large-scale consequences for visitation and hence economics.

I adopt a multimethod triangulated qualitative approach, including participant observation, standard ethnography, and retrospective analytical autoethnography (Anderson, 2006; Tolich, 2010; Buckley 2015a, 2016). That is, I apply professional knowledge within an academic context. My role and position as participant observer, ethnographer, and autoethnographer was as a long-term intermediate-skill practitioner in these adventure tourism activities, namely snowboarding (snow), surfing (surf), kiteboarding (wind), and kayaking (whitewater). This includes individual and group recreational practice, and participation in commercial adventure tourism either as client or staff (e.g., safety kayaker).

Data were collected for $>4,000$ participant days over $>40$ years. I compiled information on each of the four factors outlined above, for each of the four adventure tourism activities considered. Where relevant and available, I also compiled secondary data for individual adventure tourism sites and destinations, a multiple case study approach. Such data are derived principally from practitioner publications both printed and online, and, to a smaller extent, from mass media, social media, government reports, commercial tourism industry publications and websites, and academic publications related to specific sites and activities.

Using this approach, I aim to identify, for each of the adventure tourism subsectors considered:

1. Just what resources are required, and how resource quality is perceived by practitioners.

2. How these perceived resources depend on weather and other factors affected by climate change, and how they are expected to be modified by climate change.

3. How tourist access to adventure resources of higher and lower quality may be affected.

4. What other social, political, and market trends influence tourist choice of adventure destination.

5. Which fine-scale component of each subsector is likely to act as the most sensitive indicator of climate change.
Results

\section{Snowboarding and Skiing}

The snowsports industry has already undergone substantial changes as a result of a combination of climate change and economic factors. These changes have been most noticeable in countries with smaller snowfields and more restricted ski seasons, such as Australia. However, at least some of these changes have also affected the world's largest concentrations of ski resorts, in the European Alps and the North American Rocky Mountains.

The ways in which tourism industry has been affected by climate change, and is responding to such changes, have been studied in greater detail for the ski and snowboard sector than for any other adventure activity. For example, there are previous studies from: Norway and Sweden (Brouder \& Lundmark, 2011; Falk \& Hagsten, 2016; Moen \& Fridman, 2007); Finland and Austria (Haanpää, Juhola, \& Landauer, 2015; Landauer, Pröbstl, \& Haider, 2012); Scotland (Hopkins \& Maclean, 2014); Slovakia (Demiroglu, Kučerová, \& Ozcelebi, 2015); Canada (Dawson, Havitz, \& Scott, 2011; Rutty et al., 2015); Nepal (Nepal, 2010); Bolivia (Kaenzig, Rebetez, \& Serquet, 2016); New Zealand (Hopkins, 2014, 2015); and Australia (Cocolas, Walters, \& Ruhanen, 2016; Morrison \& Pickering, 2013; Pickering \& Buckley, 2010).

Broadly, the effects of climate change have been to reduce the reliability of high-quality snow at lower altitudes. These ski fields do still receive snowfall, but the proportion of years with short seasons and poor quality snow, and hence a high reliance on expensive artificial snowmaking, has increased. This changes the economics of these operations, because costs increase and the income-producing period becomes shorter. In addition, as the reliability of high-quality snow decreases, individual ski destinations suffer reputational damage and become less competitive, forcing them to reduce prices and hence further reducing revenue.

To combat these economic changes, resorts suffering from poorer or less reliable snowfall have taken several steps, broadly successful to date. The first is to increase artificial snowmaking so as to extend the effective operating season. However, this has limitations because of cost, lack of water, 
and the reduced number of days with below-zero nighttime temperatures, necessary for artificial snowmaking (Pickering \& Buckley, 2010). The second measure has been to promote particular destinations as family-friendly multiactivity winter sports destinations, encouraging inexperienced skiers and snowboarders to bring children for activities that do not require high-quality snow.

The third approach has been to expand the activities offered to include summer as well as winter sports, rebranding the destinations as mountain resorts rather than ski resorts. This expanded season provides greater profitability for tourist accommodation and retail outlets. It also provides limited additional clientele for ski lifts, principally by adapting the chairs or gondolas to carry mountain bikes, and using the ski runs for downhill mountain biking.

However, despite the enormous growth in the popularity of mountain biking in recent years, the numbers of mountain biking lift customers in summer do not yet match those of skiing and snowboarding lift customers in winter. Most mountain bikers have access to free trail areas closer to home than ski resorts, and are prepared to use these sites in preference, with the same bikes that they would use at the resorts. This contrasts with skiing and snowboarding, where different equipment is used for cross-country or back-country skiing, split-board snowboarding, or the combined use of snowboards and snowshoes. As a result, in skiing and snowboarding the resort-based participation greatly outweighs the non-resort-based participation, whereas in mountain biking the reverse applies.

Where land tenure and development planning approvals permit, some mountain resorts have expanded to include completely unrelated summer activities such as golf. This does not extend the lift season, but provides a substantial supply of high-paying customers for tourist accommodation and retail facilities. All of these season-extending approaches reflect: the increasing capital cost of lift and resort development; the increasing investment in accommodation, retail, and ancillary facilities; and increasing competition between resorts, to minimize basic lift ticket prices. That is, these changes would have occurred irrespective of climate change. The effect of climate change has been to hasten this process, by shortening the ski season and reducing the ability of ski resorts to rely solely on winter revenues.

The fourth approach was a major change in the basic business model, from reliance on lift ticket revenue to reliance on property development. Many mountain resorts that hold land in freehold or long-term leasehold were able to obtain additional development rights. These resorts sold or leased subdivisions for private residential, timeshare, or tourist accommodation, or constructed such developments themselves. That is, they switched to a resort-residential model, comparable to those used in coastal marinas.

The fifth approach is political. These corporations argued initially that climate change was not occurring, so as to prevent sell-off by investors while they repositioned themselves as four-season mountain resort-residential developments. Once this was achieved, they then commenced political lobbying for increased development rights and privileges, on the grounds of economic hardship as a result of climate change (Buckley, 2008a, 2008b).

All of these approaches have maintained the commercial profitability of longstanding ski resort developments, largely by reducing their reliance on high-quality snow cover. That is, they have deliberately driven a form of recreational succession or Disneyfication, so that they still have satisfied customers, though not the same customers as have visited historically. They have changed from customers who need high-quality snow to customers who are satisfied with lower quality snow or do not need snow at all.

For experienced skiers and snowboarders whose choice of destination is driven principally by snow quality, however, climate change is indeed altering the attractiveness of different sites. In general, lower latitude and lower altitude sites, which were previously attractive because of easy access and more comfortable weather conditions, are now becoming less attractive because the snow cover is poorer and less reliable. Higher altitude and higher latitude sites, where snow quality and reliability remain high, have thus become differentially attractive and hence more profitable, leading to increased investment in access and infrastructure.

Therefore, over the next few decades we are likely to see some changes in the geography of 
skiing and snowboarding as a result of climate change. However, shorter term changes are driven more by economics and politics, and their effects on access and infrastructure. For example, there is high-quality snow in the mountains of northern Iran. This destination is growing in popularity for international visitors but with political restrictions associated with visa requirements. There is good snow in parts of Russia, but concerns over safety and levels of service still set barriers to large-scale international inbound ski and snowboard tourism. There is ample snow in Greenland, but very little infrastructure, high costs, and uncertain weather.

Some of these barriers are overcome by the upmarket heliski and heliboard sector, which operates at much lower volumes and much higher prices than resort-based snow tourism. Currently, the most heavily visited heliski destinations are in the mountains of southwestern Canada, where the world's two largest heliski operators are based. There are smaller operations in Alaska, Colorado, Utah, New Zealand, Peru, India, Russia, Greenland, and elsewhere. Although the large Canadian companies operate out of purpose-built lodges, many of the others rely on existing hotels or backcountry lodges, built for summer activities such as fishing or wildlife watching. Their capital investment is thus much smaller than the large-scale resort residential developments.

Heliski and heliboard operators are not entirely mobile, because of access, terrain, permits, safety, and the economics of helicopter charter. Even so, we can anticipate that as the geography of snow quality changes, the heliski sector will be the first to respond. This applies particularly because the heliski and heliboard market depends heavily on marketing the highest quality untracked powder snow. The geography of the heliski/heliboard sector is thus a leading indicator of the effects of climate change on adventure tourism.

In tracking the effects of climate change on skiing and snowboarding, therefore, we have two separate sets of indicators, each confounded by unrelated commercial and political factors. For high-volume fixed-site resorts, there is a strong trend to diversify revenue streams to reduce reliance on high-quality snowfall, but this trend is also driven by other commercial factors (e.g., maximizing return on very large fixed capital investment). This trend applies particularly for lower latitude, lower altitude resorts where the effects of climate change are most significant to date, but these are also the resorts with greatest opportunities for summer mountain tourism.

There is also a trend for aggregation of resort operating companies into larger and larger commercial entities (Siegler, 2016). This provides some hedging against climate change by increasing the geographical spread of sites controlled by single corporations, in case customers shift destinations between seasons. Again, however, this consolidation is commonplace in many industry sectors. Overall, therefore, it is difficult to disentangle the effects of climate change from other commercial considerations, especially at single sites. It is only by following large-scale patterns in visitor numbers and preferences, in conjunction with year-by-year records of climate, snowfall, snowpack, and snow quality, that we can expect to unravel these different drivers.

At the other end of the skiing and snowboarding industry, the much more mobile helitourism sector has both greater client pressure, and fewer obstacles, in moving to new geographic areas. We may therefore expect to see the geography of heliskiing and heliboarding change more rapidly in response to climate change than the geography of large resorts. Even in the helitour sector, however, there are substantial investments in individual sites that companies are unlikely to relinquish unless their operations become unprofitable. The principal consideration is the history of negotiations to obtain exclusive operating permits across large areas of high-quality terrain. It is these permits that are the most bankable component of a commercial heliski business and justify the investment of capital to construct luxury lodges.

Therefore, we may anticipate that commercially successful heliski and heliboard operators will adopt two separate strategies to respond to climate change. The first is to expand their clientele at their existing operations. Even in poor snow years, heliskiing and heliboarding generally provide far better snow conditions than resort skiing and snowboarding, because they operate on largely untracked snow. Therefore, heliski operators market at ski resorts and gateway airports to increase demand for their products and maintain prices.

The second strategy is to explore new locations, by marketing new and especially exclusive 
opportunities to their existing clientele, many of whom are extremely wealthy and well able to afford premium prices. We can anticipate that large well-known heliski and heliboard companies with well-established reputations will not use their own names directly in these explorations, so as to avoid any reputational risk if they prove unsatisfactory. Instead, we may anticipate that these companies may support such new ventures indirectly, by providing their most trusted and experienced heli-guides with access to client lists and helicopter charter contracts, and by cross-marketing within their own marketing materials. Such approaches have already been adopted in some cases.

If new destinations prove successful, we can anticipate that the larger operators will then incorporate them into their routine offerings. Alternatively, if new destinations are developed successfully by small independent companies, we can anticipate that larger operators will then seek to buy out those independents. There are indeed indications that all these expectations are being fulfilled. Again, however, they may simply reflect good business practices to expand both markets and products, irrespective of climate change.

In addition, the availability of new heliski and heliboard destinations is determined by human as well as physical geography. There are practical factors such as access and infrastructure, including the availability of reliable helicopters and pilots. There are also legal and political factors, such as the ability to obtain operating permits, to conduct business in the country concerned, and for clients to obtain visas. Therefore, changes in the geography of heliski and heliboard tourism may well be influenced by climate change and they may also be controlled by unrelated commercial and political factors. Perhaps only the owners of the operations concerned know which of these influences predominate.

\section{Surfing, Sailboarding, and Kiteboarding}

Surfing depends on surf, and the availability, quality and reliability of surfable waves differs enormously between sites, at both regional and local scales (Buckley, 2002, 2006; Espejo, Losada, \& Méndez, 2014; Scarfe, Healy, \& Rennie, 2009). To create rideable surf requires: incident waves; a seafloor topography that will cause the waves to peel rather than collapse; and calm conditions or offshore winds to create a clean and glassy wave face.

The best incident waves commonly occur on coastlines that face large expanses of open ocean. These receive waves generated by storms or winds hundreds or thousands of kilometers away. As those waves propagate across the ocean from the area where they were initially generated, the wave trains become more highly organized, with increasingly regular height and spacing. When they reach the receiving coastline, they arrive as regular long-period swell, with regular patterns of smaller and larger wave sets, and a simple wave shape with no secondary features. The longer the upwind fetch, the better organized the incident wave on the receiving coastline. There are many mathematical models that plot and predict the propagation of waves, as a function of weather conditions over entire oceans, and these are used to forecast surf for recreational and professional surfers and surf events.

Once an incident swell reaches a receiving coastline, the conversion of swell to surf depends on ocean floor bathymetry and topography. At the same time, shorelines composed of mobile sediment, such as sand, gravel, or coral rubble, are themselves modified by incident surf, so their local-scale planform and bathymetry vary depending on recent wave history (Buckley, 2008a; Clifton, Ware, Coverdale, \& Hanson-Boyd, 2013; Kūle, Haller, Varjopuro, \& Alberth, 2013; Raybould, Anning, Fredline, \& Ware, 2015). Bedrock coastlines are not themselves directly changed by recent surf history. However, there are many surf breaks where a rocky headland controls the shape of a sandbar, but the actual wave breaks along the sand rather than the rock itself. In such cases, even though recent surf history does not affect the rocky headland, it does affect the quality of the surf break by modifying the adjacent sandbar. The point breaks on Australia's Gold Coast provides good examples of this.

Whether rock, reef, rubble, or sand, the detailed topography of the sea floor, relative to water depth and incident wave shape, determines how the waves break. At the simplest level, the shape of a breaking wave is determined by the vertical slope, horizontal angle, and water depth over the seafloor feature that is causing the wave to break. Thus, for example, a vertical obstruction protruding above water level, such as a cliff, simply reflects the incident wave 
back to sea. A vertical obstruction that ends below water level, such as a reef or rock ledge, causes the incident wave to break either sharply or gently depending on the swell height relative to water depth. A very gently shelving shoreline creates spilling waves, where the topmost section crumbles into whitewater, and the wave energy dissipates gradually. Depending on the energy of incident waves, gently shelving beaches may experience either accretion or erosion from the effects of surf. Depending on water depth, a more steeply shelving shoreline causes the top of the incident swell to pitch and plunge outwards, creating a hollow breaking wave shaped like a pipe, tube, or barrel.

If the direction of the incident wavetrain is normal to the shelving underwater feature, so that the entire wave meets the underwater obstruction simultaneously, then the wave will fold over and collapse everywhere at the same time. This is known to surfers as a close-out. If incident waves meet the underwater feature at an angle, however, then the wave will break sequentially from one end towards the other, creating good conditions for surfing. The angle between the incident waves and the underwater feature, known as the peel angle, determines how fast the breaking section moves along the wave. Surfers of different ability can perform different types of surfing maneuvers on waves of different size, steepness, and speed.

The third major factor affecting surf quality is wind, which affects the fine-scale shape of the wave as it breaks. Under calm conditions or light offshore winds, the wave face will be smooth, known to surfers as a clean wave. For large powerful swells, a strong offshore wind can render the breaking section of the wave steeper or, in surfing terminology, more hollow. Onshore wind, however, creates crumbling waves, less steep and more ragged. Skilled surfers can still ride these waves, using a variety of aerial or semiaerial maneuvers such as boosts and floaters, but clean waves are much preferred. Depending on wind speed and direction, diagonal onshore, longshore, or slightly offshore winds are preferred for sailboarding, and diagonal onshore winds for kiteboarding. These are considered below.

All of these components and mechanisms affecting wave shape and surf quality are infinitely variable, and the summary above is but the merest outline. For example, it is commonplace for coastlines to receive multiple swells simultaneously, of different sizes and from different directions, and these interact to form more complex breaking surf. As incident waves meet an underwater obstruction and begin to break, the forward propagation speed of the breaking section is reduced, so the wave becomes refracted. This is known to surfers as a bending wave. This effect is accentuated where waves break on underwater features that are themselves curved, such as the fringing reefs of small tropical islands.

When a wave is propagating across deep water, only the waveform moves forward, and the water itself does not. Once the wave breaks and crumbles into whitewash, however, the water itself moves physically towards the shore. When it subsequently flows back towards the ocean, this creates currents, known as rips, which may flow parallel, normal or diagonal to the shoreline. These rips affect the shape of subsequent breaking waves. Underwater bathymetry is rarely regular, so few waves break in a perfect or ideal shape. Each wave has different sections, which may be fast, slow, fat, hollow, clean, or crumbling, and every wave is different.

All these factors, except the baserock topography of coastlines and ocean floors, depend on weather, climate, and climate change. Swell is generated principally by atmospheric low-pressure systems. Larger, more intense, longer lasting and slower moving lows produce larger and more consistent swells. Any change in climate that affects the location, intensity, duration, frequency, and seasonal timing of atmospheric low-pressure systems necessarily also affects the geography, seasonality, and quality of surf.

Different surf tourism destinations commonly offer different types and qualities of swell at different times of year, and this affects their attractiveness and consequently their prices, customer volume, and net revenue. Where storms track close to coastlines, they create storm surge, a localized increase in mean sea level caused by reduced atmospheric pressure. Where this is coupled with large swell and high tides, it can create a very different pattern of swells and surf than occurs when swell arrives from low-pressure systems that are too far away to create storm surge or affect local wind conditions on the receiving coastline.

For sedimentary and mixed coastlines, storm conditions can also create substantial changes in 
ocean bedforms, changing the surf in ways that persist well after the storm itself has died away. Such changes are especially significant where storms generate swells from a different direction to prevailing conditions. On sandy coastlines, this can create substantial changes in shoreline planform. Large storms can also transport sediment past headlands, into estuaries, or even to the edge of the continental shelf, where it can be lost completely from the nearshore seafloor zone.

Climate change is affecting the world's oceans, as well as its atmosphere and weather patterns. The three principal effects are: sea level rise; ocean warming; and ocean acidification. Increases in mean sea level have already occurred worldwide and are continuing, possibly at an accelerating rate, but not uniformly: the rate is higher at some coastal locations than others. Although the short-term effects of increases in mean sea level are much smaller than those associated with changes in storm patterns, the long-term effect is to modify shoreline and nearshore sediment transport processes, contributing to changes in surf breaks. Increases in mean sea level also act as an addition to tide height, at all stages of the tidal cycle. The proportional addition in more significant in microtidal than macrotidal regions.

Climate change is warming the oceans as well as the atmosphere. Heat is transferred through conduction and convection, and also by increased direct radiation, where cloud cover is reduced. Reciprocal heat transfers between atmosphere and ocean are one of the causes of increased storminess. In addition, increased temperatures in the shallow oceans, and particularly the more frequent and severe extreme temperature events in the tropical oceans, have led to widespread coral bleaching events in the world's tropical reefs. At the same time, increasing atmospheric carbon dioxide concentrations are increasing the oceanic concentrations of dissolved carbon dioxide, leading to acidification. This acidification is contributing to the death of hard corals, and their gradual erosion and replacement by soft corals and algae (Reyes-Nivia, Diaz-Pulido, Kline, Guldberg, \& Dove, 2013). These combined effects are likely to change the configuration of reef breaks over the next few decades, with consequent effects on surf quality.

At present, changes in access to surf breaks are driven principally by legal, political, and economic factors (Buckley, Guitart, \& Shakeela, 2017; O’Brien \& Ponting, 2013). There may be potential cases in the future where access roads on public easements are cut by coastal erosion, exacerbated by climate change, and the roads could not be replaced because surrounding lands are privately owned. Any such cases are currently very much in a minority, but may potentially increase in the future. It is also possible that where access to particular surf breaks is through public protected areas, any future climate-related increase in fire frequency could also lead to access restriction. However, such cases are likely to remain relatively uncommon.

The effects of climate change on sailboarding and kiteboarding include all of those relating to surfing, with the additional factor of wind speed and direction. Different sailboarding and kiteboarding sites and destinations have very different wind regimes, created by different meteorological conditions. There are storm winds and sea breezes, trade winds and gorge winds, lake winds and katabatic winds, the harmattan of northwestern Africa and the levanter of southern Spain, and very many more. Winds vary by place, season, time of day, and other weather conditions. Some winds are predictable and others are not. Some sailboarders and kiteboarders prefer flat water for speed sailing; others prefer wind chop on lakes or rivers for jumps and aerial maneuvers; others prefer ocean surf for wave riding and big airs.

Climate change predictions are not yet sufficiently accurate or detailed to specify how wind regimes are likely to change at a local scale. Although atmospheric circulation patterns are a key component of climate models, they are commonly calculated at relatively broad spatial scales, and seasonal rather than short-term timescales. It will probably prove easier to predict changes for regions that have powerful and stable seasonal patterns in wind regime, with reliable current forecasting, than for areas where wind regimes are more variable and short-term weather forecasting less reliable.

The effects of climate change on surfing, sailing, and kiteboarding conditions will be felt first through changing geography and frequency of extreme weather events creating very large swells. These very large waves are not part of mainstream recreational and commercial surfing. They are ridden only by sponsored professional surfers using 
tow-in equipment, commonly with boat and helicopter support. Some of these waves are far offshore, and do not break at all except during the largest swells. We can anticipate that the effects of climate change may become noticeable for sponsored professional surfers, surf movies, and big-wave competitions before they become noticeable on surf tourism more broadly.

\section{Whitewater Rafting and Kayaking}

Whitewater paddlesports depend on river flows, and hence on rainfall patterns, as well as on terrain and topography. Worldwide, by far the majority of whitewater rafting and kayaking sites rely on unregulated rivers where stream flow depends entirely on rainfall and runoff. The proportion of sites that use rivers whose flow is regulated by dam releases is much smaller, but some of those sites receive particularly high-volume use.

Dam-release sites may be considered in two categories. Most dams were built to store water for agricultural irrigation, urban water supply, or hydroelectric power generation. For these, the timing and volume of water releases are determined by those uses, without consideration of tourism or recreation. Urban water supply dams may not release any water downstream at all, except when they are filled to overflowing. Large irrigation dams commonly release water only as required by downstream growers, creating large flows during a short growing season, with very low flows during the rest of the year.

In some countries, hydroelectric power provides part of the base load, and these dams release water continuously. In other countries, base load is provided from thermal power stations, and hydroelectric power is used to provide peak load, because output can be adjusted at much shorter timescales than for thermal power stations. In these cases, water is commonly released in two pulses each day, coinciding with morning and evening peak power demand. Depending on the length of the river corridor downstream, these pulses become smoothed and attenuated as they travel down river. Perhaps the best known example of this type of river flow is the Grand Canyon of the Colorado, with pulses created by twice-daily releases from the Glen Canyon Dam.
In some countries, all three categories are required to release a minimum flow to maintain in-stream ecosystems, but such flows are rarely enough to provide for recreational whitewater rafting and kayaking.

In a few countries and a few cases, rivers have been dammed either specifically to provide water flows for rafting and kayaking, or jointly to provide for recreational as well as other uses. In China, for example, many of the watercourses used for piaoliu ziyou are dammed upstream specifically to provide regulated water flows for commercial tourism (Buckley, McDonald, Duan, Sun, \& Chen, 2014). The Tully River in north Queensland, Australia, downstream of the Tully-Millstream Dam, releases a short timed pulse each day for use by commercial raft tour operators, though this is not its principal function.

Dams are built specifically to change the seasonal or diurnal patterns of water flow downstream, where run-of-river water flows are otherwise inadequate for the intended purpose. Any change in climate that affects rainfall patterns will also affect future releases. This applies particularly in those areas of the world where droughts are intensifying. In addition, as the world's human population continues to grow, with consequent increases in demand and competition for water, there is continuing and increasing pressure to build more dams. This pressure is intensified both by increasing demand for electrical power and by political pressure to transition from carbon-intensive thermal power stations to renewable sources including hydroelectricity.

The overall net result is that more and more rivers are dammed in more and more places, and dam releases are less frequent and lower in volume. This applies particularly for high-volume, high-gradient rivers in deeply incised channels in mountainous terrain, and especially where river flow does not vary greatly from year to year, even if it may be strongly seasonal. These are the watercourses that provide the greatest and most economically efficient opportunities to store large volumes of water at minimum cost, with lowest losses to surface evaporation or overtopping, and the smallest number of dry years. This contrasts with rivers running through broad low-gradient floodplains, with high variability in flow between years, where it is difficult to capture and store water effectively, and 
the terrain gradient provides insufficient head for hydroelectric power generation.

Unfortunately for the whitewater rafting and kayaking sector, the rivers that are preferred for dam construction are precisely the same as those that provide the best and most reliable recreational rapids. Therefore, climate change is likely to reduce opportunities for whitewater rafting and kayaking, by increasing the number of good whitewater rivers that are dammed, and reducing the volume and frequency of usable dam-release flows.

However, currently most whitewater rafting and kayaking rely on free-flowing rivers without dams. Some of these flow consistently year-round and others only seasonally or intermittently. Many midvolume rivers in mountainous cool temperate regions, for example, provide the best conditions for whitewater rafting and kayaking during spring snowmelt, when substantial volumes of precipitation stored as snowpacks are released over a relatively short period of time. If either winter snowfall or spring temperatures change to any significant degree, this will modify the water flows in these rivers, and hence the available period, and river conditions, for whitewater rafting and kayaking.

In tropical and subtropical rivers, in contrast, seasonal flow patterns are caused by the alternation of wet and dry seasons, with peak flows during monsoon rains. Again, if climate change modifies the timing, duration, intensity, or total rainfall during monsoons or wet seasons, this will affect river flow and the consequent opportunities for whitewater rafting and kayaking.

As with other types of adventure tourism, the whitewater rafting and kayaking sector is dependent on aspects of human as well as physical geography. In particular, it requires access to rivers, either at single points for so-called park-and-play kayaking on standing waves, or more commonly, at put-in and take-out points for downriver trips, whether single or multiday. Access requires both the physical ability to get to the watercourse at a point where boats can be launched or landed, and also the legal right to use those access points, the economic ability to do so from the tourist's hometown or country, and the political and social conditions to make the journey safely. If climate change leads to increasing conflict, either over water itself or over other independent issues, this may well reduce the accessibility of relevant river sections worldwide.

All river flows, including snowmelt runoff, monsoon flows, and dam releases, are very strongly dependent on rainfall, and rainfall patterns are already changing in many parts of the world as a consequence of global climate change. For all commercial whitewater rafting and kayaking tours that operate only during a limited season, dependent on river flows, climate change is already creating commercial consequences.

Commercial whitewater tours are finely turned to particular water flow volumes in individual rivers. These affect: launch and takeout points; overnight campsites; downstream progress and total trip length; safety precautions and the time taken to scout individual rapids; the size, type, and capacity of watercraft used; and group size and guide-to-client ratios. All of these factors, as well as the length of the operating season, influence the commercial viability of individual tour operations, and the companies that run them.

The relative profitability of different types of whitewater tourism product, on different sections of different rivers, thus depends on detailed water flow patterns, and hence on climate. As with rainfall patterns more generally, it is difficult to differentiate whether the particular patterns in any one season may or may not reflect longer term climate change. However, multiyear trends in rainfall and river flows are indeed reflected in the changing geography of the commercial rafting and kayaking adventure tourism sector.

\section{Conclusions}

The various types of adventure tourism that depend on wind, snow, and waves will all be affected by climate change. These effects will include: those due directly to changes in weather patterns; those caused by indirect effects through changing human geography and political ecology; and those created by market reactions to both of these. The direct effects are likely to be somewhat damped, as human societies in general, and tourism and tourists in particular, find ways to adapt and respond to modified weather patterns. As noted above, the most expert 
subsectors of each adventure tourism activity are likely to provide the first indication of climate change effects, because they are most sensitive to the quality of the natural resources used.

However, the market-related effects are likely to be amplified, principally by substitution between different destinations. Tourists and their travel agents select individual destinations for particular adventure activities by comparing a large basket of different factors. The relative importance of different factors, such as access, price, and social effects, differs considerably between different subsectors of the adventure tourism market.

For more experienced adventure tourism practitioners, the quality of snow, surf, wind, or whitewater is the primary consideration (Buckley, 2012, 2015b, 2016). That is, these individuals would prefer to save up for several years if necessary, in order to enjoy the best location and conditions for their chosen activity. They are constantly concerned to compare the reputation of different alternative destinations, with strong reliance on social media. Within frameworks for destination image, their perceptions are influenced more powerfully by autonomous and organic rather than induced sources of information.

Under these conditions, a single poor season at any site yields negative e-WOM, which can quickly trigger a major change in destination image and reputation, altering the geography of tourist flows so as to favor competing destinations offering the same activity. These market-driven mechanisms are already in operation, and the consequences of climate change will simply add one further factor.

Indeed, when tour operators are asked about their responses to longer term climate change, their actual responses relate only to short-term weather, and its effects on cancellations either by clients or by the operator for safety reasons. Given the difficulties in distinguishing statistically whether any short-term sequence of weather events does or does not reflect longer term climate change, it will be difficult to measure directly how climate change affects most adventure tour businesses.

There are a few exceptions where climate change has a cumulative effect on physical features, and this affects tourism operations that rely on those features. For example, in some parts of the world there are commercial hiking tours or boat trips to look at the tongues of glaciers. Where those glaciers are retreating, those tours are affected. Similarly, where mountaineering routes cross icefalls, climate change can create noticeable and persistent increases in risk. This has occurred, for example, at the Khumbu Icefall on the principal route to climb Mount Everest.

For those adventure tourism activities involving surf and snow, wind and whitewater, however, the first observable effects of climate change are likely to be due to changes in destinations preferred by more experienced tourists seeking optimum conditions. Such changes will be detectable by correlating: multiyear sequences in weather, wave, and water flow conditions; social media commentary on sites and destinations; travel agent perspectives on changing preferences; new locations advertised by leading commercial tour operators in each subsector; and actual tourist numbers for relevant enterprises at different destinations.

Future research in this field could thus take a number of different directions. To correlate the changing geography of adventure tourism directly with climate change will require large multiyear sets of data on tourist numbers, climate parameters, and a range of commercial variables to distinguish the many different potential drivers of tourist numbers at different countries, destinations, and companies.

A less definitive but more immediate approach would be to ask the owners of adventure tour companies how their businesses have been affected by changes in the quality of the natural resources on which they depend, namely snow, surf, wind, and water. This approach also provides opportunities to examine the interactions between physical and human geography, and the effects of competition between companies and destinations within the relevant adventure tourism subsectors. In parallel with this approach, surveys or interviews with individual adventure tourists could help to reveal how they are responding to perceived changes in the quality of natural resources at different sites.

Finally, we could search for indicators in the most climate-sensitive components of each of these adventure tourism subsectors. As outlined above, these might include the geography of heliski and heliboard tourism and professional big-wave surfing, and the timing and length of season for rivers reliant on snowmelt runoff or monsoon rains. 


\section{References}

Anderson, L. (2006). Analytic autoethnography. Journal of Contemporary Ethnography, 35, 373-395.

Becken, S. (2013). Measuring the effect of weather on tourism a destination- and activity-based analysis. Journal of Travel Research, 52, 156-167.

Brouder, P., \& Lundmark, L. (2011). Climate change in Northern Sweden: Intra-regional perceptions of vulnerability among winter-oriented tourism businesses. Journal of Sustainable Tourism, 19, 919-933.

Buckley, R. C. (2002). Surf tourism and sustainable development in Indo-Pacific Islands. I. The industry and the islands. Journal of Sustainable Tourism, 10, 405-424.

Buckley, R. C. (2006). Adventure tourism. Wallingford, UK: CAB International.

Buckley, R. C. (2007). Adventure tourism products: Price, duration, size, skill, remoteness. Tourism Management, 28, 1428-1433.

Buckley, R. C. (2008a). Climate change: tourism destination dynamics. Tourism Recreation Research, 33, 354-355.

Buckley, R. C. (2008b). Misperceptions of climate change damage coastal tourism: Case study of Byron Bay, Australia. Tourism Review International, 12(1), 71-88.

Buckley, R. C. (2010). Adventure tourism management. Oxford, UK: Elsevier.

Buckley, R. C. (2012). Rush as a key motivation in skilled adventure tourism: Resolving the risk recreation paradox. Tourism Management, 33(4), 961-970.

Buckley, R. C. (2015a). Autoethnography helps analyse emotions. Frontiers in Psychology, 6, 209.

Buckley, R. C. (2015b). Adventure thrills are addictive. Frontiers in Psychology, 6, 1915.

Buckley, R. C. (2016). Qualitative analysis of emotions: fear and thrill. Frontiers in Psychology, 7, 1187.

Buckley, R., Gretzel, U., Scott, D., Weaver, D., \& Becken, S. (2015). Tourism megatrends. Tourism Recreation Research, 40(1), 59-70.

Buckley, R. C., Guitart, D., \& Shakeela, A. (2017). Contested surf tourism resources in the Maldives. Annals of Tourism Research, 64, 185-199.

Buckley, R. C., McDonald, K., Duan, L., Sun, L., \& Chen, L. X. (2014). Chinese model for mass adventure tourism. Tourism Management, 44, 5-13.

Buckley, R., \& Shakeela, A. (2014). Climate change hotspots in the tourism sector. In P. Burton (Ed.), Responses to climate change: Lessons from an Australian hotspot (pp. 77-84). Melbourne, Australia: CSIRO.

Clifton, C. A., Ware, D., Coverdale, S., \& Hanson-Boyd, C. (2013). Climate change risks for Victoria's surf coast. In Coasts and Ports 2013: 21st Australasian Coastal and Ocean Engineering Conference and the 14th Australasian Port and Harbour Conference (p. 204). Barton, Australia: Engineers Australia.

Cocolas, N., Walters, G., \& Ruhanen, L. (2016). Behavioural adaptation to climate change among winter alpine tourists: an analysis of tourist motivations and leisure substitutability. Journal of Sustainable Tourism, 24(6), 846-865.
Dawson, J., Havitz, M., \& Scott, D. (2011). Behavioral adaptation of alpine skiers to climate change: Examining activity involvement and place loyalty. Journal of Travel \& Tourism Marketing, 28(4), 388-404.

Day, J., Chin, N., Sydnor, S., \& Cherkauer, K. (2013). Weather, climate, and tourism performance: a quantitative analysis. Tourism Management Perspectives, 5, 51-56.

Demiroglu, O. C., Kučerová, J., \& Ozcelebi, O. (2015). Snow reliability and climate elasticity: case of a Slovak ski resort. Tourism Review, 70(1), 1-12.

Espejo, A., Losada, I. J., \& Méndez, F. J. (2014). Surfing wave climate variability. Global and Planetary Change, 121, 19-25.

Falk, M., \& Hagsten, E. (2016). Importance of early snowfall for Swedish ski resorts: Evidence based on monthly data. Tourism Management, 53, 61-73.

Goh, C. (2012). Exploring impact of climate on tourism demand. Annals of Tourism Research, 39(4), 1859-1883.

Gössling, S., \& Hall, C. M. (2006). Uncertainties in predicting tourist flows under scenarios of climate change. Climatic Change, 79(3-4), 163-173.

Gössling, S., Scott, D., Hall, C. M., Ceron, J. P., \& Dubois, G. (2012). Consumer behaviour and demand response of tourists to climate change. Annals of Tourism Research, 39(1), 36-58.

Haanpää, S., Juhola, S., \& Landauer, M. (2015). Adapting to climate change: Perceptions of vulnerability of down-hill ski area operators in Southern and Middle Finland. Current Issues in Tourism, 18(10), 966-978.

Hall, C. M. (2015). Mountaineering and climate change. In G. Musa, J. Higham, \& A. Thompson-Carr (Eds.). Mountaineering tourism (pp. 240-243). Oxon, UK: Routledge.

Hopkins, D. (2014). The sustainability of climate change adaptation strategies in New Zealand's ski industry: A range of stakeholder perceptions. Journal of Sustainable Tourism, 22(1), 107-126.

Hopkins, D. (2015). The perceived risks of local climate change in Queenstown, New Zealand. Current Issues in Tourism, 18(10), 947-965.

Hopkins, D., \& Maclean, K. (2014). Climate change perceptions and responses in Scotland's ski industry. Tourism Geographies, 16(3), 400-414.

Kaenzig, R., Rebetez, M., \& Serquet, G. (2016). Climate change adaptation of the tourism sector in the Bolivian Andes. Tourism Geographies, 18(2), 111-128.

Kūle, L., Haller, I., Varjopuro, R., \& Alberth, J. (2013). Climate change impacts on coastal tourism in the Baltic Sea region. Coastline Reports, 21, 91-132. Retrieved from http://spicosa.databases.eucc-d.de/files/documents/00 001153_CR_21_pp91-132.pdf

Landauer, M., Pröbstl, U., \& Haider, W. (2012). Managing cross-country skiing destinations under the conditions of climate change: Scenarios for destinations in Austria and Finland. Tourism Management, 33(4), 741-751.

Moen, J., \& Fredman, P. (2007). Effects of climate change on alpine skiing in Sweden. Journal of Sustainable Tourism, 15(4), 418-437. 
Morrison, C., \& Pickering, C. M. (2013). Perceptions of climate change impacts, adaptation and limits to adaption in the Australian Alps: The ski-tourism industry and key stakeholders. Journal of Sustainable Tourism, 21(2), 173-191.

Nepal, S. K. (2013). Mountain tourism and climate change: implications for the Nepal Himalaya. Nepal Tourism and Development Review, 1(1), 1-14.

O’Brien, D., \& Ponting, J. (2013). Sustainable surf tourism: A community centered approach in Papua New Guinea. Journal of Sport Management, 27, 158-172.

Pickering, C., \& Buckley, R. C. (2010). Climate response by the ski industry: The shortcomings of snowmaking for Australian resorts. Ambio, 39(5-6), 430-438.

Raybould, M., Anning, D., Fredline, L., \& Ware, D. (2015). Urban beach venues: Vulnerability and sustainability in the face of climate change. International Journal of Event Management Research, 10(1), 84-105.

Reyes-Nivia, C., Diaz-Pulido, G., Kline, D., Guldberg, O. H., \& Dove, S. (2013). Ocean acidification and warming scenarios increase microbioerosion of coral skeletons. Global Change Biology, 19, 1919-1929.

Rosselo-Nadal, J. (2014). How to evaluate the effects of climate change on tourism. Tourism Management, 42, 334-340.

Rutty, M., Scott, D., Johnson, P., Jover, E., Pons, M., \& Steiger, R. (2015). Behavioural adaptation of skiers to climatic variability and change in Ontario, Canada. Journal of Outdoor Recreation and Tourism, 11, 13-21.

Scarfe, B. E., Healy, T. R. \& Rennie, H. G. (2009). Researchbased surfing literature for coastal management and the science of surfing-a review. Journal of Coastal Research, 253, 539-557.

Siegler, K. (2016). Vail resorts to buy Canada's Whistler Blackcomb for $\$ 1.06$ billion. Retrieved from http://www. npr.org/sections/thetwo-way/2016/08/08/489244335/ vail-resorts-to-buy-canadas-whistler-blackcomb-for-106-billion

Tolich, M. (2010). A critique of current practice: Ten foundational guidelines for autoethnographers. Qualitative Health Research, 20, 1599-1610. 